\title{
Destitution
}

\section{Who and where are the poorest of the poor?}

Sabina Alkire, Mihika Chatterjee, Adriana Conconi, Suman Seth and Ana Vaz | June 2014

In 2014, we have used more extreme MPI indicators to shine a light on hundreds of millions of people who each day face grinding hardships difficult for most of us to imagine: the destitute, or poorest of the poor. The good news is that where data are available, we can see strong progress being made to improve the lives of the destitute, particularly in the poorest countries.

\section{WHAT IS ‘DESTITUTION’?}

What constitutes extreme poverty is a hot topic as discussions on the post-2015 development goals intensify. Debates over different poverty lines rage on; if you have $\$ 1.25$ a day, are you still one of the 'poorest of the poor'? What if you have $\$ 2$ a day? How do we know who to focus resources on in order to ensure the poorest are not 'left behind'?

With a multidimensional measure of poverty, the picture quickly focuses with uncomfortable clarity. Have you watched two of your children - or even more - die? Are you forced to practise open defecation because you have no sanitation? Has no member of your family completed more than a single year at school? And if these occur together, could anyone argue that you are not experiencing an extreme form of poverty?

The Global MPI has always revealed disparities in the intensity of poverty being experienced by those identified as multidimensionally poor. If a person is deprived in one fifth to one third of the weighted indicators the index uses, they are considered 'Vulnerable to Poverty'. If they are deprived in more than half, they are identified as being in 'Severe Poverty'.

This year, we also shine a light on the poorest of the poor the destitute. Those identified as 'Destitute' are already MPI poor. In addition, they are deprived in at least one-third of the same weighted indicators, but according to more extreme criteria than those used to identify the MPI poor - including the examples mentioned above (see table). Also, the destitute may possess no assets whatsoever - not even a radio or mobile phone. At least one member of the household may be severely undernourished, and accessing safe drinking water requires a lengthy round-trip of more than 45 minutes.

\section{WHO ARE THE DESTITUTE?}

Data on destitution are currently available for 49 of the 108 countries analysed in the Global MPI 2014. These countries cover much of South Asia, including Afghanistan, Bangladesh, India, Nepal and Pakistan. We also have data on vast swathes of Sub-Saharan Africa, covering Burkina Faso, Burundi, Cameroon, Central African Republic, Congo, Cote d'Ivoire, DR Congo, Ethiopia, Gabon, Ghana, Guinea-Bissau, Malawi, Mozambique, Niger, Nigeria, Rwanda, Senegal, Sierra Leone, South Africa, Swaziland, Tanzania, Togo, Uganda and Zimbabwe. Two Arab countries are covered (Iraq and Tunisia), as well as four countries in East Asia and the Pacific (Cambodia, Indonesia, Lao and Vietnam), six from Europe and Central Asia (Armenia, Bosnia and Herzegovina, Kazakhstan, Macedonia, Serbia and Tajikistan) and eight from Latin America and the Caribbean (Belize, Guyana, Haiti, Honduras, Mexico, Nicaragua, Peru and Suriname).

\section{Key Findings}

- India is home to 343.5 million destitute people $28.5 \%$ of the population is destitute. And overall in South Asia, over $\mathbf{4 2 0}$ million people are destitute.

- In Niger, $\mathbf{6 8 . 8 \%}$ of the population is destitute the highest share of any country. In Ethiopia this figure is $\mathbf{5 8 . 1} \%$ and Burkina Faso, $\mathbf{5 7 . 5 \%}$.

- Nearly three quarters of destitute people in the countries for which we have data are also in severe MPI poverty: they are deprived in $50 \%$ or more of the MPI indicators.

- Over 638 million people are destitute across only 49 countries analysed thus far.

\section{- Across these 49 countries half of MPI poor people are destitute}

- Ethiopia reduced the percentage of destitute people 30 percentage points from 2000-2011

- Of the 34 countries for which we have time-series data, eight of the top ten performers at tackling destitution were LICs or Least Developed Countries 


\section{What does it mean to be destitute?}

- $46 \%$ of the destitute don't have anyone in their home with more than one year of schooling

- $36 \%$ of the destitute have a primary-aged school child out of school

- $41 \%$ of the destitute live in a household in which at least one woman/man has lost two or more children

- $67 \%$ of the destitute have someone at home with severe malnutrition

- $71 \%$ of the destitute don't have electricity to turn on their lights

- $90 \%$ of the destitute practise open defecation to relieve themselves

- $40 \%$ of the destitute don't have clean water, or must walk 45 minutes to get it

- $83 \%$ of the destitute have only a dirt floor

- $98 \%$ of the destitute cook with wood, dung, or straw

- $69 \%$ of the destitute don't even own a mobile phone or a radio - nor a refrigerator or bike or television

- All of the destitute are deprived in at least one-third of the weighted indicators

These 49 countries concentrate 1.2 billion out of the total 1.6 billion MPI poor in the complete set of 108 countries. Across the 49 countries included, half of MPI poor people are destitute. This has obvious implications for the goal of eliminating extreme poverty, widely mooted as achievable post-2015. It would be but faint success if the reduction of income poverty globally were not complemented by the eradication of these deprivations.

Those identified as destitute by the Global MPI 2014 suffer a range of hardships difficult for most of us to imagine (see box, 'What does it mean to be destitute?'). Over $41 \%$ of them have experienced the loss of two or more children.
Almost 67\% have at least one household member who is severely malnourished. More than $46 \%$ of the destitute don't have any household member that has completed even one year of schooling and in 36\% of them all primary school-aged children are out of school. Also, more than $71 \%$ have no access to electricity and a similar proportion don't possess even the most basic assets - no bicycle, no radio, no telephone (not even a mobile), no refrigerator, no television, no motorbike; certainly no car or truck. Almost $90 \%$ practice open defecation, with all the feelings of shame, fear, insecurity and humiliation that accompany it. In addition, nearly $40 \%$ of them don't have access to safe drinking water or the water source is more than 45 minutes away, roundtrip; more than $83 \%$ of the destitute in these 49 countries have inadequate flooring and almost $98 \%$ of them use solid cooking fuels for cooking.

Out of all those identified as destitute in our 49 countries, nearly three-quarters of them $-72.8 \%$ - also experience severe MPI poverty; in other words they are deprived in at least half of the MPI indicators, as well as one-third of the destitution indicators. Within this limited set of only 49 countries, this condition already affects over 465 million people. ${ }^{1}$

\section{WHERE ARE THE DESTITUTE?}

By far the largest number of destitute people - 'destitute' are to be found in India: $\mathbf{2 8 . 5 \%}$ of the population, which is over 340 million people. ${ }^{2}$ Furthermore, in India, fully 53\% of MPI poor people are destitute. If we include the other countries in South Asia for which we have data (Afghanistan, Bangladesh, Nepal and Pakistan), we find that over $\mathbf{4 2 0}$ million people in South Asia are destitute. ${ }^{3}$ The highest incidence of destitution in South Asia is in Afghanistan, where $37.7 \%$ of the population are destitute.

In Sub-Saharan Africa, we have data for only 24 countries but these already house 200 million destitute people. Country

\section{Table 1: The deprivation thresholds of those who are both MPI poor and destitute}

\begin{tabular}{|c|c|c|c|}
\hline Dimension & Indicator & Deprived if... & $\begin{array}{c}\text { Relative } \\
\text { Weight }\end{array}$ \\
\hline \multirow[b]{2}{*}{ Education } & Years of schooling & No household member has completed at least one year of schooling $(>=1)$. & $1 / 6$ \\
\hline & $\begin{array}{l}\text { Child School } \\
\text { Attendance }\end{array}$ & No child is attending school up to the age at which they should finish class 6 . & $1 / 6$ \\
\hline \multirow[b]{2}{*}{ Health } & Child Mortality & $\mathbf{2}$ or more children have died in the household & $1 / 6$ \\
\hline & Nutrition & $\begin{array}{l}\text { Severe undernourishment of any adult }\left(\mathrm{BMI}<17 \mathrm{~kg} / \mathrm{m}^{2}\right) \text { or any child }(-3 \text { standard } \\
\text { deviations from the median). }\end{array}$ & $1 / 6$ \\
\hline \multirow{6}{*}{$\begin{array}{l}\text { Living } \\
\text { Standard }\end{array}$} & Electricity & The household has no electricity (no change). & $1 / 18$ \\
\hline & $\begin{array}{l}\text { Improved } \\
\text { Sanitation }\end{array}$ & There is no facility (open defecation). & $1 / 18$ \\
\hline & Safe Drinking Water & $\begin{array}{l}\text { The household does not have access to safe drinking water, or safe water is more than a } \\
\mathbf{4 5 - m i n u t e ~ w a l k ~ ( r o u n d ~ t r i p ) . ~}\end{array}$ & $1 / 18$ \\
\hline & Flooring & The household has a dirt, sand, or dung floor (no change). & $1 / 18$ \\
\hline & Cooking Fuel & $\begin{array}{l}\text { The household cooks with dung or wood (coal/lignite/charcoal are now non- } \\
\text { deprived). }\end{array}$ & $1 / 18$ \\
\hline & Assets & The household has no assets (radio, mobile phone, etc.) and no car. & $1 / 18$ \\
\hline
\end{tabular}


experiences in the region vary dramatically. In South Africa, for example, only $9.3 \%$ of the people who are MPI poor are also destitute, whereas in Niger, $77.1 \%$ of the MPI poor people are destitute. On average across these 24 African countries over $53.3 \%$ of MPI poor people are also destitute. The country with the highest number of destitute people in Africa is Ethiopia, with 50.6 million destitute people or $58.1 \%$ of the population.

Outside South Asia and Sub-Saharan Africa the number of destitute people drops dramatically; the country with the highest number of destitute outside these two regions is Indonesia, with 9.7 million people or $4 \%$ of the population being destitute; the country with the highest rate of destitution is Haiti, where $18.1 \%$ of the population are destitute

Over the coming months we will be making data on destitution available for nearly 50 more of the countries covered by the Global MPI; check www.ophi.org.uk/ multidimensional-poverty-index for updates.

\section{HOW IS DESTITUTION CHANGING?}

We also have data on how destitution has changed during 37 time periods in 34 different countries, including India, Nepal, Indonesia and Rwanda. ${ }^{4}$ In 31 of these time periods, and 28 of these countries, there was a significant reduction in destitution, ${ }^{5}$ while in Armenia, Egypt, Jordan, Madagascar and Pakistan there was no change.

The good news is that in nearly all of the countries analysed, destitution is being reduced in relative annualized terms ${ }^{6}$ faster than multidimensional poverty. In Ethiopia, Guyana, Niger and Tanzania that is also true in absolute terms. This suggests that in these countries at least, the poorest of the poor are being reached, and there is potential for those who are destitute to 'catch up'.

Strikingly, the countries doing best at tackling destitution are mostly Low Income and Least Developed Countries (LICs and LDCs); the largest absolute reduction in the destitution MPI was seen in Ethiopia, followed by Niger, Ghana, Bolivia, Rwanda, Tanzania, Nepal, Haiti, Bangladesh and Zambia - all of them LICS or Least Developed Countries except Ghana and Bolivia.

Between 2000 and 2011, Ethiopia reduced the percentage of the population who were destitute by a massive 30 percentage points, and reduced intensity among the destitute by fully 10 percentage points. That is, the average poor person in 2011 was deprived in nearly two standard of living indicators less than the average poor person had been in 2000. During the first five years, reduction sped forward at $\mathbf{3 . 3}$ percentage points each year, with significant reductions in all indicators, and the strongest gains in water, sanitation, and educational variables. From 2005 to 2011 progress slowed slightly, but the reduction was still impressive at $\mathbf{2 . 2}$ percentage points of the population annually. Niger's rate of destitution-MPI reduction matched that of Ethiopia 2005-2011.

In the large majority of the countries, destitution is more prevalent in rural areas. Fortunately, it is also in those areas

\section{Destitute in Delhi - Bibi Ayesha's story}

Bibi Ayesha lives in a box-like structure on stilts near a temple in Delhi, India. Injured in an accident years ago, she is unable to walk and gets around on a handpedalled tricycle. For sanitation she relies on government restrooms near her makeshift home,

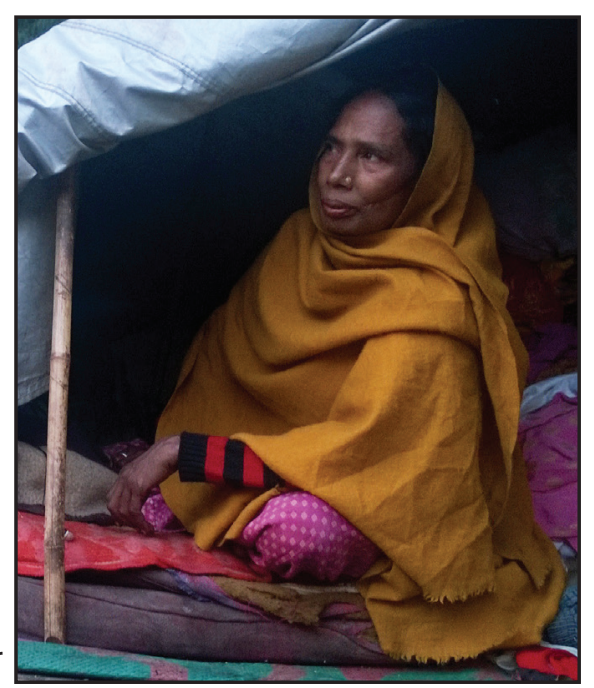
which has no electricity or water. Her flooring is not dirt or sand - although it could hardly be called proper flooring!

She earns a little money by cleaning a nearby homeless shelter and collecting alms in front of the temple, but most of the money is spent on medication for her chronic respiratory condition. What little food she can afford, she cooks over wood on a little mud stove and shares with her mentally ill son.

Bibi is deprived in the shaded indicators shown in her poverty profile, and as such is multidimensionally poor. She is also deprived in $7 / 18$ of the more extreme indicators shown in the table, and is therefore identified as destitute.

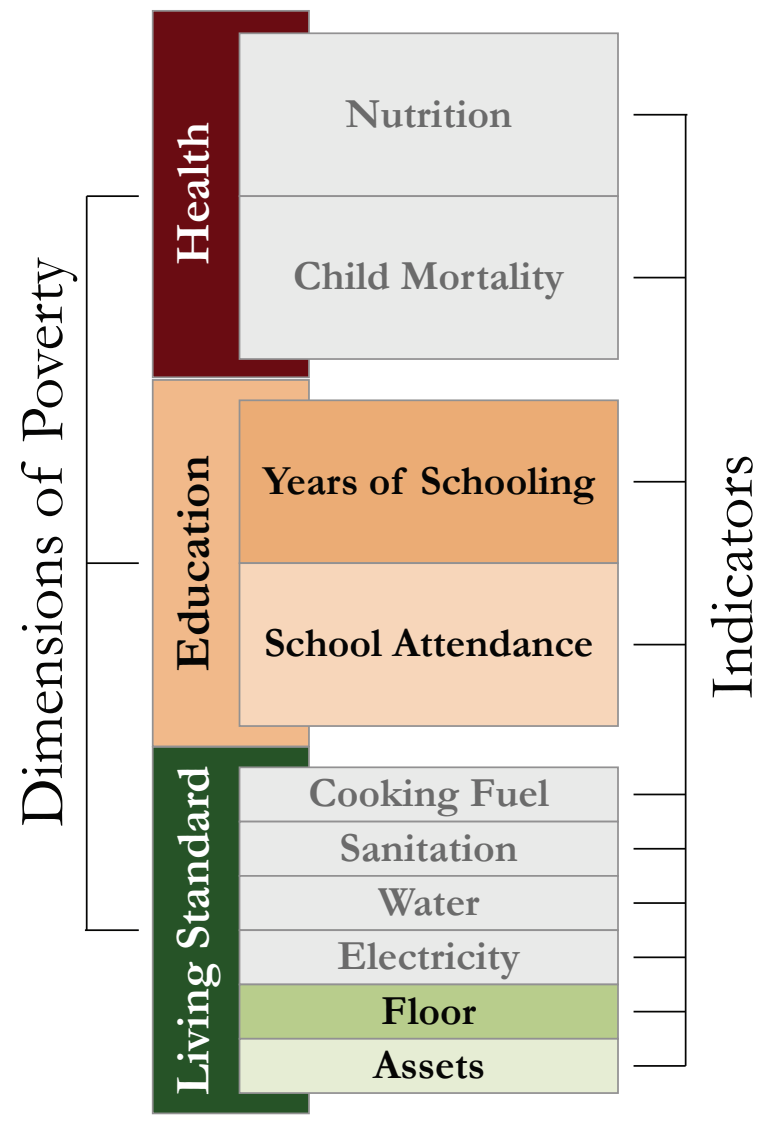




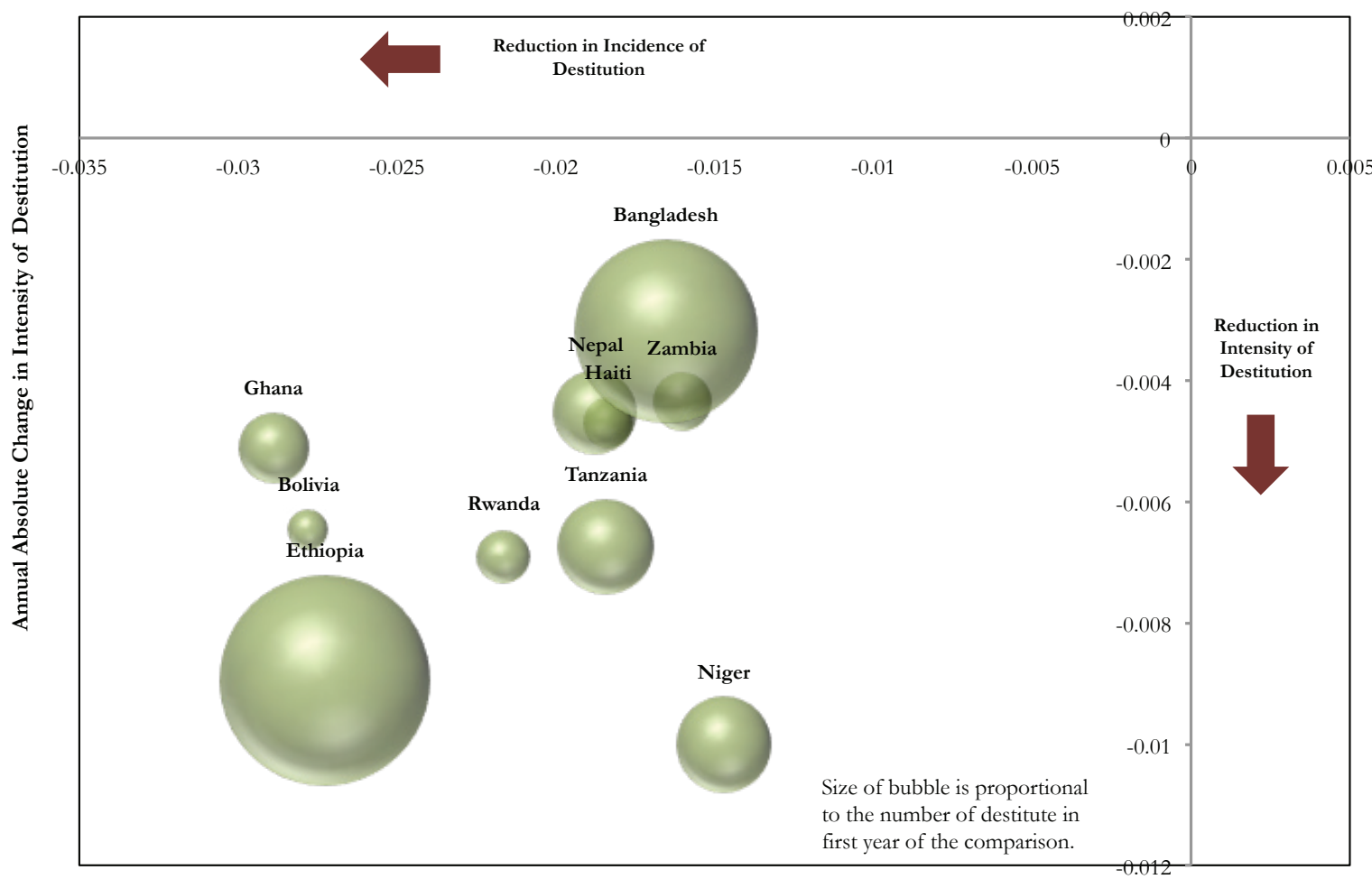

Annual Absolute Change in Incidence of Destitution

that most countries have made more important progress in absolute terms. Rural reductions in destitution were statistically significant in 27 countries, ${ }^{8}$ whereas urban reductions were significant only in 20 countries - pointing out a relative urbanization of poverty. In terms of indicators, the majority of the countries registered significant improvements in sanitation and children mortality. This suggests that health and sanitation policies are contributing to improve the lives of the poorest of the poor.

This success in tackling destitution in some of the world's poorest countries sparks hope that progress is being made, and that concerted efforts post-2015 really can result in there being 'no one left behind'. For now, destitution - with all the grinding hardship, pain and privations it entails - remains a reality for hundreds of millions of people, and an issue on which policymakers the world over must surely set clear sights.

\section{Oxford Poverty \& Human Development Initiative (OPHI)}

Oxford Department of International Development (ODID)

Queen Elizabeth House (QEH)

University of Oxford, Mansfield Road

Oxford OX1 3TB UK

\section{Telephone: $+44(0) 1865271915$}

Email: ophi@qeh.ox.ac.uk

Website: $\quad$ www.ophi.org.uk

OPHI gratefully acknowledges support from research councils, non-governmental and governmental organisations, and private benefactors. For a list of our funders and donors, please visit our website: www.ophi.org.uk.

\section{NOTES}

1. Note that nearly a third of destitute people $-32 \%$ in these countries - are deprived in $50 \%$ or more of the destitution indicators. This is 204 million people across these 49 countries. Of these, 101 million live in India, and 126 million in our 5 South Asian countries.

2. All population aggregates for the 49 countries use 2010 population data (UNDESA 2013). Note that India's NFHS data were most recently collected in 2005/6; newer data, when available, may lower these estimates.

3. As additional countries from other regions are added, this is likely to diminish.

4. These 71 datasets have been harmonized for strict comparability, so the numbers may not match the global MPI figures for destitution exactly.

5. We use a significance level of 0.05 , and thus in these 28 countries we do not include Senegal, where the reduction in the destitution MPI was statistically significant only at 0.1 level.

6. The relative rate of change is the difference in levels across two periods as a percentage of the initial period. The annualized relative rate of change is the compound rate of reduction per year between the initial and the final periods.

7. According to the DAC figures for 2012 and 2013 aid flows.

8. Significant by t $\alpha=0.05$. In Bangladesh and Ethiopia this reduction was significant in both periods of comparison.

\section{REFERENCES}

Alkire, S., A. Conconi and S. Seth (2014): 'Measuring Destitution in Developing Countries: An Ordinal Approach for Identifying Linked Subsets of the Multidimensionally Poor', OPHI Research in Progress.

Alkire, S., Conconi, A., and Seth, S. (2014): 'Multidimensional Poverty Index 2014: Brief Methodological Note and Results', Oxford Poverty and Human Development Initiative, University of Oxford.

Alkire S, Roche, J. M. and Vaz, A. (2014), 'Multidimensional Poverty Dynamics: Methodology and Results for 34 Countries'. Mimeo. 